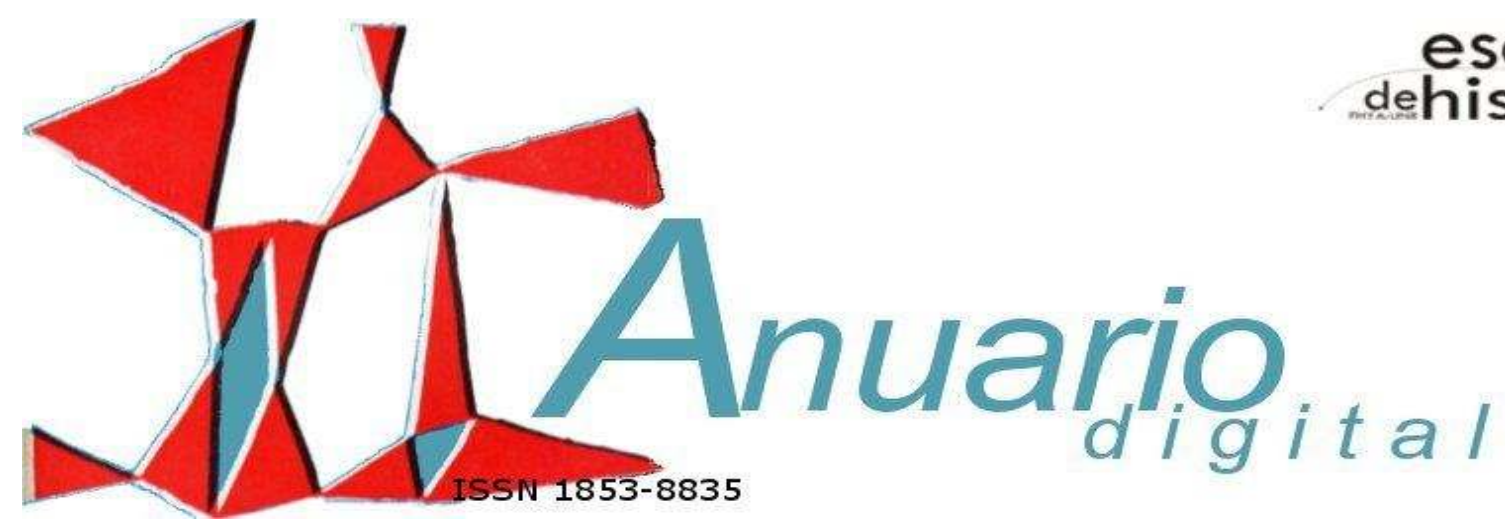

\title{
GAUCHOS Y CATÓLICOS. EL ORIGEN DE LAS PEREGRINACIONES GAUCHAS A LA BASÍLICA DE LUJÁN, BUENOS AIRES, 1945
}

MATÍAS EMILIANO CASAS*

(Universidad Nacional de Tres de Febrero / CONICET);

mecasas@untref.edu.ar

\section{RESUMEN}

La integración entre sectores de la Iglesia Católica y dirigentes de agrupaciones tradicionalistas dio origen en 1945 a la primera peregrinación gaucha -institucionalizada y orgánica- a la basílica de Luján. Con el paso de los años se consolidó una práctica que se sostiene en la actualidad. El estudio de esas manifestaciones permite, por un lado analizar la circulación de una representación del gaucho vinculado indefectiblemente a la religión católica, y por otro lado atender el rol protagónico desempeñado por Monseñor Anunciado Serafini y los círculos criollos El Rodeo y Martín Fierro. La afinidad sostenida por el "obispo peregrino" con los centros evocativos del gaucho resultó clave para la concreción de esas actividades. La figura del hombre de la pampa encontraba, entonces, una nueva reafirmación ya no sólo como "símbolo de las virtudes patrióticas", sino como portador de los valores evangélicos.

Palabras clave: gaucho - tradición - Iglesia Católica - Anunciado Serafini - Virgen de Luján

ABSTRACT Gauchos and catholics. The origin of the gaucho pilgrimage to the Basilica of Luján, Buenos Aires 1945

\footnotetext{
* Profesor, Magister Doctorando en Historia
} 
The integration between sectors of the Catholic Church and traditionalist groups in 1945 gave rise to the first gaucho pilgrimage -organic and institutionalized- to the Basilica of Luján. Over the years, the practice was stabished and it stands until now a days. The study of these expressions allows, by one side, analyze the movement of the gaucho representation inevitably linked to the Catholic religion, and on the other hand deals with the leading role played by Bishop Anunciado Serafini and Creoles circles El Rodeo and Martin Fierro. The affinity sustained by the "Bishop Pilgrim" with Gaucho evocative centers was the key to the realization of these activities. The figure of the man of the pampas was, then, a new reaffirmation not only as "a symbol of the patriotic virtues," but as a bearer of catholic values.

Key words: gaucho - tradition - Catholic Church - Anunciado Serafini - Virgin of Luján

\section{Introducción}

Hacia mediados de la década del cuarenta los centros tradicionalistas que evocaban las costumbres rurales y la figura del gaucho como arquetipo de la nacionalidad argentina experimentaban un auge en su organización y actividades. Agrupaciones como El Rodeo, de la Provincia de Buenos Aires, expresaban desde sus prácticas una marcada ligazón entre las tradiciones camperas y los elementos católicos que formaban parte constitutiva de las mismas. Esa adhesión a los preceptos de la Iglesia se manifestaba en recurrentes celebraciones religiosas que contaban con la participación de numerosos socios. En ese contexto, durante 1945, se produjeron una serie de acontecimientos que concluyeron en la institución de la primera peregrinación gaucha a la basílica de Luján.

La integración entre sectores de la Iglesia Católica y dirigentes de agrupaciones tradicionalistas consolidó una práctica que se sostiene en la actualidad. El estudio de esas manifestaciones permite, por un lado analizar la circulación de una representación del gaucho vinculado indefectiblemente a la religión católica, y por otro lado atender el rol protagónico desempeñado por Monseñor Anunciado Serafini. La afinidad sostenida por "el Obispo peregrino" con los centros evocativos del gaucho resultó clave para la concreción de esas actividades. La figura del hombre de la pampa encontraba, entonces, una nueva reafirmación ya no sólo como "símbolo de las virtudes patrióticas", sino como portador de los valores evangélicos.

\section{8}

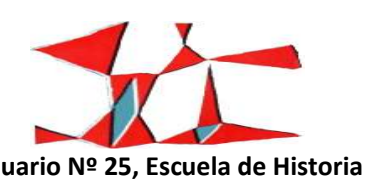

Revista Digital № 4, Facultad de Humanidades y Artes, Universidad Nacional de Rosario, 2013

ISSN 1853-8835 
La religiosidad del gaucho se definió como un territorio en disputa. Como para otras de sus caracterizaciones resultaba imposible la uniformidad de criterios y opiniones. Varios de los escritores más reconocidos del país elaboraron, en diferentes etapas, distintas aproximaciones sobre la fe del gaucho. Vicente Fidel López expresó: “El gaucho era un ser completamente descreído. Su religión era un deísmo sui generis que se reducía a figurar una cruz con los dedos o besar el escapulario en los momentos difíciles de la vida." ${ }^{1}$ Joaquín Víctor González lo definía, principalmente, como un ser supersticioso: "Si arraigaban en su alma, con fuerza, las supersticiones estúpidas desgarradas por el alejamiento de los centros urbanos." ${ }^{2}$ Leopoldo Lugones, en una etapa que lo encontraba opuesto al cristianismo cuando redactó la recopilación de sus conferencias en el libro El Payador, desestimó la posibilidad de ligar al gaucho con la religión: "El gaucho no fue religioso, al faltarle en su vida aventurera las sugestiones de la miseria y el miedo, así como el sinsabor de la existencia causado por las civilizaciones decadentes." ${ }^{3}$ Décadas más tarde, el sacerdote cordobés Francisco Compañy desarrolló una teoría basada en el análisis del Martín Fierro para corroborar la adhesión del gaucho a los valores cristianos y católicos. ${ }^{4}$ La institución de las peregrinaciones gauchas representa un antecedente importante en el lineamiento propuesto por Compañy y una práctica consolidada en orden a establecer una indefectible ligazón entre el arquetipo de la tradición y la Iglesia Católica.

Este proceso tuvo como resultado paralelo la fundación del Círculo Criollo "Martín Fierro" en la localidad de Jáuregui bajo el padrinazgo de Julio Steverlynck, el belga que fundara la empresa textil Flandria. La emergencia de esta agrupación introduce una dimensión analítica en referencia a los vínculos gestados por esta nueva organización y por su continua suscripción al ideario religioso que se exaltaba recurrentemente a pocos metros en la ciudad de Luján. Martín Fierro y El Rodeo se autoproclamaron custodios y garantes de esas manifestaciones actualizándolas año a año y otorgándoles continuidad.

El presente artículo tiene la pretensión de contribuir a los estudios que analizaron la figura del gaucho. La principal motivación que conlleva este estudio consiste en vislumbrar cómo se construyó la representación del gaucho católico en el marco de la institución de las peregrinaciones al santuario de

\footnotetext{
${ }^{1}$ López, Vicente Fidel; Panoramas y retratos históricos; Ed. Jackson; Buenos Aires; 1938; p. 19.

${ }^{2}$ González, Joaquín; La Tradición nacional; Buenos Aires; 1912; T. II; p. 225.

${ }^{3}$ Lugones, Leopoldo; El Payador; Ed. Centurión; Buenos Aires; 1916; p. 124.

${ }^{4}$ Compañy, Francisco; La fe de Martín Fierro; Ediciones Theoría; Buenos Aires; 1963.
}

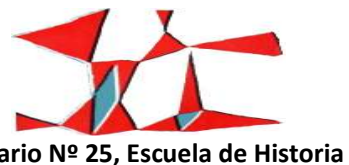


Luján. Estudiado desde esta perspectiva, el trabajo se inserta en el campo de investigaciones sobre los usos del pasado, en particular del gaucho y la tradición. Asimismo, la metodología para recrear esa representación -peregrinaciones, almuerzos populares, danzas, prácticas ecuestres- evidencia un proceso de ocupación católica del espacio público que se vincula a los estudios recientes sobre el "movimiento católico" desde la perspectiva de la historia social y cultural. Si bien el tópico no constituye la preocupación central de este análisis, se considera que la desarticulación del entramado que dio origen a esas peregrinaciones resultará provechosa para los trabajos que se propongan profundizar al interior de las movilizaciones católicas y las representaciones en torno a la virgen y el santuario de Luján. Prácticas socioculturales como la aquí presentada resultaron canales de consolidación para que el gaucho se erigiese como "arquetipo de la nacionalidad argentina". Con un discurso nacionalista que se presentaba impregnado de evocaciones patrióticas fueron, también, espacios de integración para inmigrantes que buscaban adherir a las propuestas identitarias de esos centros tradicionalistas.

\section{Círculo Criollo "El Rodeo", católicos y peronistas}

El primer centro tradicionalista que se documenta en los archivos data de finales de siglo XIX en la ciudad de Montevideo, Uruguay. En septiembre de 1894 un grupo de personas desfilaron a caballo por la avenida 18 de Julio y, liderados por Elías Regules, anunciaron la constitución de la sociedad criolla La Tapera. Regules era un académico de la facultad de medicina que se desempeñó también como escritor nativista colaborando con la revista El Fogón, importante publicación del género gauchesco. ${ }^{5}$ Lo interesante para resaltar aquí sobre esos episodios fundacionales de las agrupaciones criollas remite a las normativas que regularon desde el comienzo estos espacios de sociabilidad y reafirmación de las identidades nacionales. Como bien lo analiza Ángel Rama en Los Gauchipolíticos Rioplatenses, el discurso de esos fundadores estuvo atravesado por la cuestión de asociar al gaucho con la "esencia de la raza uruguaya" y con una particular perspectiva de los inmigrantes y su interacción con las nuevas costumbres. Regules manifestaba: "Las naciones europeas rellenas de gente [...] nos han vomitado sus menesterosos para descargarse de una molestia insoportable." ${ }^{6}$ Esta consideración, como se profundizará más adelante, no representó una

\footnotetext{
${ }^{5}$ Sobre Elías Regules ver, entre otros, Centanino, Horacio; Modernización y Cultura en el Uruguay: una lectura teatral: Regules, Falco, de las Carreras; Melibea Ediciones; Montevideo; 2000. Regules, Elías; Versos Criollos; Ministerio de Instrucción Pública y Previsión Social; Montevideo; 1965.

${ }^{6}$ Rama, Angel; Los Gauchipolíticos Rioplatenses; Centro Editor de América Latina; Buenos Aires; $1994 ;$ p. 149.
}

260

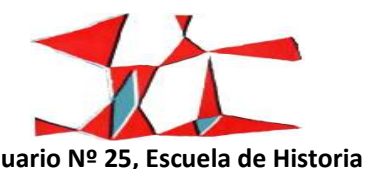

Revista Digital № 4, Facultad de Humanidades y Artes, Universidad Nacional de Rosario, 2013 ISSN 1853-8835 
consigna estática y permanente para los futuros tradicionalistas. Durante el período aquí estudiado, las agrupaciones emergentes sostuvieron una actitud de apertura hacia todo aquel que adoptara las normas institucionales.

La presencia de esas consignas normativas en los orígenes de los centros criollos regulaba las actividades y la organización interna. La primera reunión de la asociación fundada por Regules fue en una quinta ambientada por carteles que expresaban, por ejemplo, la leyenda: "Está prohibido hablar de política y de religión". ${ }^{7}$ El interdicto ocluía dos de las temáticas más recurrentes para los centros tradicionalistas de la década del cuarenta. Si se detiene el análisis en la agrupación El Rodeo, actualmente ubicada en el partido de Moreno en la Provincia de Buenos Aires, podría esbozarse una reformulación de la consigna en: "prohibido no hablar de política ni de religión", sus prácticas, discursos y vinculaciones la definieron para ese tiempo en una entidad católica y peronista. ${ }^{8}$

El Circulo Criollo El Rodeo se constituyó hacia fines de la década del treinta en la localidad de Santos Lugares, partido de General San Martín. Con el objetivo de "sostener en todo momento y en cualquier lugar la Tradición Criolla", según lo expresa el acta fundacional, comenzó con sus actividades que, de manera gradual, irían abarcando cada vez más protagonismo en las instituciones zonales, provinciales y nacionales. ${ }^{9}$ Si se realiza un breve repaso por los documentos que atestiguan su interacción con otras entidades resaltará la presencia de: clubes sociales, cooperadoras de escuelas, sociedades de fomento, cuerpos de bomberos, centros tradicionalistas, organismos municipales, etc. ${ }^{10}$ Su participación se veía comprometida, en la mayoría de los casos, con una serie de números artísticos y deportivos en festejos de aniversarios, fechas patrias u homenajes. El Rodeo se caracterizaba por presentar un cuerpo de baile de danzas nativas que era recurrentemente solicitado. Es conveniente aclarar que el proceso de consolidación del folklore ligado a la cuestión nacional había recibido el impulso desde las políticas educacionales que lo colocaban

\footnotetext{
${ }^{7}$ Ibidem; p. 152.

${ }^{8}$ Las referencias a la ligazón católica y peronista de El Rodeo aparecen, entre otros, en: Invitación del Círculo Católico de Obreros de Luján, 22 de julio de 1946. Archivo del Círculo Criollo El Rodeo (de ahora en adelante CCER). Libro de Comunicaciones. Nota institucional al Gobernador de la Provincia de Buenos Aires, Domingo Mercante, 28 de junio de 1947. Archivo del CCER, Libro de Comunicaciones.

${ }_{9}^{9}$ Acta fundacional CCER Archivo del CCER, Libro de Actas.

${ }^{10}$ Invitación de la Municipalidad de San Isidro, 25 de julio de 1946. Petitorio de la Cooperadora de la Escuela N 10 de la Matanza, 10 de agosto de 1946. Agradecimiento del Club "José Hernández" de Villa Bosch, 25 de noviembre de 1941. Agradecimiento de Bomberos Voluntarios de Gral. San Martín, 4 de junio de 1942. en Archivo del CCER. Libro de Comunicaciones.
}

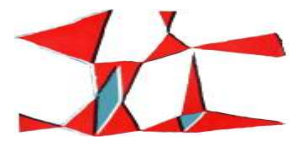

Anuario № 25, Escuela de Historia Revista Digital № 4, Facultad de Humanidades y Artes, Universidad Nacional de Rosario, 2013 ISSN 1853-8835 
como contenido obligatorio en las escuelas y el recorrido realizado desde el norte del país financiado por las elites dirigenciales. ${ }^{11}$ Las festividades recurrían también a eventos deportivos para atraer un mayor número de espectadores. Las carreras de sortija en primera medida y los partidos de pato, sobre todo a partir del decreto que lo erigía como deporte nacional en $1953,{ }^{12}$ alcanzaban gran protagonismo entre las celebraciones, que generalmente finalizaban con un desfile evocativo en el cual se lucían los socios de las agrupaciones vestidos a la usanza gaucha.

Como se mencionó anteriormente, dos características puntuales se destacan de la presentada agrupación. Se referirá aquí de modo sintético a la cuestión política porque resulta vital para comprender las posibilidades de expansión que desarrolló la entidad. Los primeros años de su existencia evidenciaron un proceso de organización interna que ocupó todos los esfuerzos y actividades. El silencio político caracterizó el período hasta el año 1945, sus contactos con las autoridades municipales respondían a permisos o consultas reglamentarias. ${ }^{13} \mathrm{El}$ advenimiento del peronismo trastocó todas las dimensiones de la vida social en Argentina y el Círculo Criollo El Rodeo no se mantuvo al margen de esto. ${ }^{14}$ Con una adhesión práctica y discursiva a la figura de Perón los dirigentes de la agrupación desarrollaron numerosas actividades destacadas a exaltar su obra de gobierno. La ligazón entre la entidad y el Justicialismo podría ameritar un estudio particular que la analice. Empero, no es pertinente para este trabajo extenderse mucho más sobre esta cuestión, sólo se puntualizarán algunas expresiones que testifican lo mencionado. En una solicitud de ingreso como socio, un postulante animaba en 1951: “iViva la Patria! ¡Viva José de San Martín! y iViva Perón!". ${ }^{15}$ En tiempos del Segundo Plan Quinquenal, el secretario privado del Gral. Perón agradeció la nota enviada por El Rodeo manifestando la adhesión a la propuesta del Gobierno. ${ }^{16}$ Vicente Veláz, quién alcanzó

\footnotetext{
${ }^{11}$ Sobre el folklore ver, entre otros, Chamosa, Oscar; The Argentine Folklore Movement. Suger Elites, Criollo Workers, and the Politics of Cultural Nationalism, 1900-1955; The University of Arizona Press; Arizona y Cattaruzza, Alejandro; Los usos del pasado; Sudamericana; Buenos Aires; 2007; pp. 120-137.

${ }^{12}$ Decreto N 17.468. Revista Pato. Federación Argentina de Pato. 1977.

${ }^{13}$ Comunicado de la Intendencia de San Martín, 4 de septiembre de 1942. Correspondencia del socio Sol Mentaste, 19 de diciembre de 19441. Archivo del CCER. Libro de Comunicaciones.

${ }^{14}$ Sobre peronismo ver, entre otros, Plotkin, Mariano; Mañana es San Perón: propaganda, rituales políticos, y educación en el régimen peronista (1946-1955); Ariel Historia Argentina; Buenos Aires; 1994. Cosse, Isabella; Estigmas de nacimiento: peronismo y orden familiar, 1946-1955; FCE; Buenos Aires; 2006. Acha, Omar; Los muchachos peronistas: orígenes olvidados de la juventud peronista; Planeta; Buenos Aires; 2011 y Fiorucci, Flavia; Intelectuales y Peronismo: 1945-1955; Biblos; Buenos Aires; 2011.

${ }^{15}$ Correspondencia de Andrés Martínez, postulante a socio. 19 de septiembre de 1951. Archivo del CCER. Libro de Comunicaciones.

${ }^{16}$ Notificación del Secretario Privado del Presidente de la Nación, Jorge Ballofet, 12 de junio de 1953. Archivo del CCER. Libro de Comunicaciones.
}

262

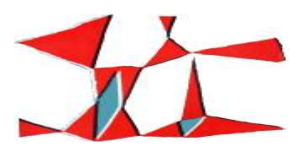

Anuario № 25, Escuela de Historia Revista Digital № 4, Facultad de Humanidades y Artes, Universidad Nacional de Rosario, 2013 ISSN 1853-8835 
la presidencia del Círculo Criollo en las elecciones de 1951 fue el encargado de entregarle en mano una ofrenda floral a Perón en las demostraciones del agro con motivo de la ley de jubilación y el estatuto del peón. "El Vasco", como lo llamaban en El Rodeo recordando sus antepasados foráneos, declaró entonces: "Perón, es como decir Padre de la Patria y ejemplo de la Argentinidad". ${ }^{17}$

La segunda característica particular que se destacaba en esa agrupación de Santos Lugares era su originaría adhesión a las practicas religiosas de la Iglesia Católica. La problemática que planteaba la catolización de la figura del gaucho, a partir de la actuación de esos tradicionalistas, era inherente a lo que los protagonistas interpretaban por "ser católico" y también a los procesos coyunturales que se desarrollaban al interior de la Iglesia. En este punto, la estructura católica de la agrupación y la posterior organización de las peregrinaciones no parecía responder a un proyecto delineado desde organismos corporativistas u otras organizaciones que emergían en el seno del catolicismo. Los integrantes de El Rodeo configuraron al gaucho como un católico de culto que comulgaba con los dogmas de la Iglesia y participaba asiduamente de los sacramentos. Para referirse al pasado pampeano, donde las prácticas católicas de los supuestos gauchos encontraban un punto de tensión en orden a la vida nómade y la ausencia de pastores que rigieran sus conductas, las apelaciones recaían sobre consideraciones valorativas. Es decir, atendiendo a los intereses de los tradicionalistas, los gauchos eran católicos en tanto conservaron en su vida errante por el desierto los valores cristianos heredados. Esta reconfiguración permite reconocer la versatilidad para definir los parámetros del "ser católico", en la coyuntura de los centros tradicionalistas el concepto involucraba los sacramentos, las manifestaciones públicas, y las pautas de conducta, en el tiempo pasado, siempre evocado desde esas agrupaciones, lo católico se remitía a tener buenas intenciones y destacar valores como la honradez y el coraje.

Desde el comienzo de sus actividades los miembros de El Rodeo se mostraron prestos a participar en diversas manifestaciones atenientes al clero y sus feligreses. Asimismo, la organización de la agrupación se fue realizando con una continua advocación a la Virgen de Luján. Cabe destacar que, en términos generales, la veneración de Nuestra Señora de Luján respondía a una política de la Iglesia Católica que durante la década del treinta se ocupó de intensificar la identidad marista como reacción al proceso de

\footnotetext{
${ }^{17}$ Recorte periodístico "Demostración del campo a Perón", s/d. "Acampó en la ciudad el trabajador de la buena tierra", Doctrina, s/f. Archivo del CCER. Libro de Prensa.
}

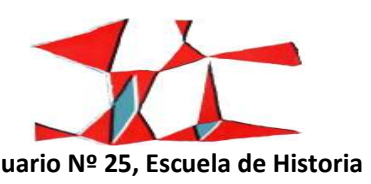


secularización. ${ }^{18}$ Una bula del papa Pio XI el 8 de diciembre de 1930 declaró a la Virgen de Luján como patrona de Argentina, Uruguay y Paraguay. La historiadora Patricia Fogelman plantea que: "el proceso de gestación de su [de la Virgen de Luján] prestigio, potencia y legitimidad viene de tiempos coloniales, se condensó fuertemente a fines del siglo XIX y ha servido en ciertos momentos de tensión social o política, para apuntalar las posiciones de la Iglesia en relación con otros poderes. ${ }^{\prime 19}$ En la veneración y difusión de la Virgen, la participación del secretario general de El Rodeo, Orlando Binaghi, resultó fundamental. "Fito", como era popularmente conocido, se caracterizaba por un amplio dominio de técnicas escultoras y sus trabajos más recurrentes remitían a imágenes religiosas. Él mismo se erigió como custodio de la capilla que se encontraba en el campo del centro criollo en la que se celebraban, no solo las misas dominicales, sino también bautismos, comuniones y matrimonios. ${ }^{20}$ El centro tradicionalista ofrecía clases de catecismo para los niños y abría sus puertas para casamientos temáticos donde "los gauchos y las chinas" se comprometían como miembros de la Iglesia. ${ }^{21}$

El carácter católico de estos "gauchos" resulta clave para comprender el posterior origen de las peregrinaciones a caballo hacia el santuario de Luján. Previo al inicio en el año 1945, El Rodeo protagonizaba todo tipo de celebraciones y festivales católicos difundiendo una representación del hombre de la pampa adherida a los dogmas religiosos. "Porque conocemos su amor a la tradición gaucha de nuestro pueblo contamos con su amable presencia", expresaba la invitación de la Parroquia Santa Rita de San Isidro a la inauguración del nuevo templo. ${ }^{22}$ Un factor que posibilitó esas interacciones era la continua presencia de las carreras de sortijas en esas festividades. La especialidad de la agrupación en esas actividades incrementaba el número de eventos en los que se hacían presentes. Como lo expresó el Círculo Católico de Obreros de la ciudad de Luján, otras entidades también apelaban a "su patriotismo y su hondo sentir cristiano" para contar con su participación. ${ }^{23}$ Fiestas patronales, conmemorativas, inauguraciones,

\footnotetext{
${ }^{18}$ Fogelman, Patricia; El culto mariano en Luján y San Nicolás. Religiosidad e historia regional; Biblos; Buenos Aires; $2013 ;$ pp. 25-26.

${ }^{19}$ Ibídem; p. 28.

${ }^{20}$ Binaghi, Luis; Tras las Huellas de la Familia Binaghi; Meana Impresores; Chaco; 2000; pp. 118-119.

${ }^{21}$ Clarin; 4 de julio de 1949. Loreto. Revista quincenal de la Parroquia Nuestra Señora de Loreto; El Palomar, 1 de septiembre de 1950.

${ }^{22}$ Invitación de la Iglesia Santa Rita, San Isidro, 16 de mayo de 1944. Archivo del CCER. Libro de Comunicaciones.

${ }^{23}$ Petitorio del Círculo Católico de Obreros de Luján, 22 de julio de 1946. Archivo del CCER. Libro de Comunicaciones.
}

264

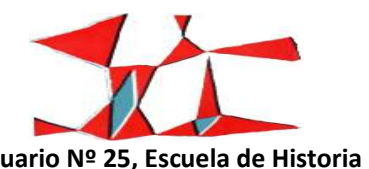


representaron entonces un antecedente de lo que se instituiría con el protagonismo del Obispo de

Mercedes a mediados de los años cuarenta. ${ }^{24}$

\section{Anunciado Serafini y la primera peregrinación gaucha}

La Iglesia Católica argentina transitaba un período complejo que involucraba en su esfera una serie de renovaciones culturales, ideologías políticas y metodologías prácticas. ${ }^{25}$ Según el historiador José Zanca los Cursos de Cultura Católica, en la década del veinte, y la Acción Católica Argentina, en la década del treinta, representaron el comienzo de una serie de numerosas instituciones que le dieron al catolicismo "su carácter de identidad colectiva". ${ }^{26}$ Desde una perspectiva política, la crisis del liberalismo posibilitó el surgimiento de alternativas que en el movimiento católico se concretaron con el proyecto de la "nueva cristiandad". El avance y la intención de recristianizar la sociedad tuvieron como brazo ejecutor a la Acción Católica. ${ }^{27}$ Si bien esa agrupación, de principios integralistas, se caracterizó por su presencia y participación en la esfera pública acaparando la organización de diversos eventos y llevando adelante actividades que involucraban diferentes instituciones, no estuvo ligada a los orígenes de las peregrinaciones aquí estudiadas. El único registro que liga a los centros que instituyeron la movilización con la Acción Católica Argentina remite a una colaboración prestada en un festejo parroquial en la localidad de Caseros. ${ }^{28}$

Los festejos, las movilizaciones y la ocupación del espacio público durante el período de entreguerras han despertado la atención de varios estudios como bien lo analiza el historiador Diego Mauro. ${ }^{29}$ En su análisis sobre la bibliografía producida recupera los aportes de la historia social y cultural

\footnotetext{
${ }^{24}$ Agradecimiento de la Comisión Pro-festejos patronales de Nuestra Señora de la Merced, Caseros, 17 de octubre de 1941. Agradecimiento de la Comisión Vecinal de Navidad, Ciudadela, 7 de diciembre de 1942. Petitorio de Nuestra Señora de los Remedios, Capital Federal, 8 de diciembre de 1944. Archivo del CCER. Libro de Comunicaciones.

${ }^{25}$ Ver, entre otros, Lida, Miranda y Mauro, Diego (coords.); Catolicismo y sociedad de masas en Argentina; 1900-1950; Prohistoria; Rosario; 2009.

${ }^{26}$ Zanca, José; “¿Primos o hermanos? Nacionalismo, integrismo y humanismo cristiano en la Argentina de los años sesenta”; en Amnis. Revue de civilisation contemporaine Europes / Amériques; № 11; 2012.

${ }^{27}$ Sobre la Acción Católica Argentina ver, entre otros, Blanco, Jessica; Modernidad conservadora y cultura política: La Acción Católica Argentina; FFyH; Buenos Aires; 2008.

${ }_{28}^{28}$ Agradecimiento de la Acción Católica Argentina-Junta Parroquial de Caseros, 16 de agosto de 1947 Archivo del CCER.

29 Mauro, Diego; "Multitudes y movilizaciones católicas en la Argentina de entreguerras: cuestiones metodológicas e historiográficas"; en PolHis; № 8; 2011; pp. 90-96. Sobre movilización y catolicismo de masas ver también Lida, Miranda; "Los orígenes del catolicismo de masas en la Argentina: 1900-1934"; en Jahrbuch für Geschichte Lateinamerikas; Bd 46; 2009. Acha, Omar; "La movilización católica de la infancia en octubre de 1943 y la educación religiosa"; en Lida, Miranda y Diego Mauro
}

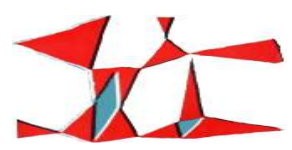

Anuario № 25, Escuela de Historia Revista Digital № 4, Facultad de Humanidades y Artes, Universidad Nacional de Rosario, 2013 ISSN 1853-8835 
para tomar distancia de las posturas tradicionalmente adoptadas desde una perspectiva política de la historia. Según el autor, la movilización católica, más allá de las ideologías y retóricas discursivas, fueron resultado de una sociedad y cultura de masas, "capaz de articular consumo, recreación, religión y espectáculo". Las peregrinaciones a caballo continuaron esa condición de espectacularidad que tan de relieve se había puesto en los congresos eucarísticos. ${ }^{30}$ Desde el recorrido hasta la misma celebración de la Eucaristía adquirían dotes llamativos para la participación popular, estimulados por variedades como las carreras de caballos y los monaguillos vestidos de gauchos.

Las demostraciones de fe en el santuario de Luján se presentaban asiduamente para la época estudiada. Distintas agrupaciones, colectividades e instituciones, realizaban sus peregrinaciones anuales con una variada convocatoria. ${ }^{31}$ La colectividad italiana, por ejemplo, realizaba sus procesiones al santuario desde 1909. El fundador de la Sociedad Católica Italiana, Domingo Repetto, fue el precursor de esas manifestaciones. Para el año 1939 contaban ya con la adhesión de varios peregrinos provenientes de distintas localidades de la Provincia de Buenos Aires y la participación de prelados argentinos e italianos como el Obispo de Iberá, Julián Martínez y el Monseñor Ireneo Calabresse. ${ }^{32}$ Más allá de esas manifestaciones, un sector de la Iglesia desarrollaba desde la década del treinta un integrismo católico que la pretendía colocar como pilar de la "argentinidad" y como fundamento de la identidad nacional. ${ }^{33}$ La representación del gaucho católico, que se reafirmaba con la institución de las peregrinaciones, se sostuvo en esos antecedentes que comulgaban, al menos desde lo discursivo, con la pretensión de consolidar la identidad argentina a través de los elementos católicos.

En la ciudad de Luján se organizaban, frecuentemente, actividades en torno a la figura de la Virgen que consistían en festejos populares con procesiones, almuerzos y espectáculos deportivos y artísticos. En abril de 1945, confluyeron en una de esas celebraciones quienes serían los protagonistas de las primeras

(coords.); Dossier "Catolicismo y política en la Argentina del siglo XX"; en Historiapolítica.com [en línea] url: http://historiapolitica.com/dossiers/catolicismoypolitica

${ }^{30}$ Galindez, Mercedes; "Prensa y cultura de movilización de masas en el Congreso Eucarístico Internacional de 1934"; en Lida, Miranda y Diego Mauro(coords.); Dossier "Catolicismo y política en la Argentina del siglo XX"; Historiapolítica.com [en línea] url: http://historiapolitica.com/dossiers/catolicismoypolitica

${ }^{31}$ El Pueblo; 30 de noviembre de 1939. El Pueblo; 4 y 5 de diciembre de 1939.

32 El Pueblo; 4 de noviembre de 1939.

${ }^{33}$ Sobre integrismo católico ver Mallimaci, Fortunato; El catolicismo argentino desde el liberalismo integral a la hegemonía militar; CEHILA; Buenos Aires; 1992 y Mallimaci, Fortunato; "Católicos nacionalistas y nacionalistas católicos en Argentina"; en Mallimaci, Fortunato y Cuccetti, Humberto (comps.); Nacionalismos y nacionalistas; Gorla; Buenos Aires; 2011.

\section{6}

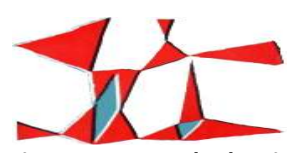

Anuario № 25, Escuela de Historia 
peregrinaciones gauchas. La cúpula dirigencial de El Rodeo se preparaba para visitar a caballo el museo gauchesco Ricardo Güiraldes en San Antonio de Areco, fundado con pretensiones de erigirse como "templo de la tradición". Acorde a lo relatado por los protagonistas, las condiciones climáticas determinaron la modificación del plan original. Binaghi junto a otros dirigentes decidieron, entonces, participar en el desfile de carretas organizado por la municipalidad de Luján. Allí encontraron a los equipos de sortija de Algodonera Flandria y Linera Bonaerense dos industrias de la localidad de Jáuregui pertenecientes a Julio Steverlynck. ${ }^{34}$ La relevancia del mencionado empresario y su influencia en la zona será abordada más adelante en vinculación a la institución que comenzaba a gestarse a partir de ese encuentro, el Círculo Criollo Martín Fierro.

La festividad culminó con el paso de los "gauchos" llevando la bandera argentina. Monseñor Anunciado Serafini, obispo de Mercedes quien había presenciado el desfile, decidió convocar a los paisanos para fotografiarse junto a ellos. ${ }^{35}$ Esa reunión improvisada derivó en una propuesta por parte del obispo para que se concrete una peregrinación anual, "los gauchos fueron los primeros devotos de la virgen" manifestó el religioso. ${ }^{36} \mathrm{El}$ obrar de Serafini amerita una serie de consideraciones particulares en pos de comprender los estímulos por él aportados. Su recorrido en la iglesia católica se había caracterizado, entre otras cosas, por trasladar con frecuencia la imagen de la Virgen de Luján hacia los pueblos del interior organizando grandes celebraciones que consistían en diversas manifestaciones de fe con procesiones, misas de campaña y entronizaciones. Se considera que la exitosa interacción entre el obispo y las agrupaciones criollas no respondió sólo a una comunión espiritual sino que existieron, al menos, dos factores que contribuyeron a solidificar el vínculo.

En primer lugar, Monseñor Serafini utilizaba un lenguaje "campechano y vulgar" que, desde sus homilías, intentaba cautivar al público presente. Según el Sacerdote José Francescutti quien compartió con él sucesivas celebraciones durante esa época: "simplificaba su mensaje porque su público era sencillo, de pocos conocimientos religiosos. No buscaba deslumbrar con ideas, giros y palabras académicas." ${ }^{37}$ José $^{-1}$ Guido Pesce fue ordenado sacerdote por el mismo obispo en 1944, y desde ese momento compartió su

\footnotetext{
${ }^{34}$ El Telar; Flandria. Año XLIII, Nº 427. 1977-1978.

${ }^{35}$ El Telar; Flandria. $\mathrm{N}^{\circ} 162.1945$.

${ }^{36}$ El Telar; Flandria. Año XLIII, N 427. 1977-1978.

37 "Los viajes del Obispo Peregrino" s/d. Archivo del Círculo Criollo Martín Fierro (en adelante CCMF). Libro de Prensa.
}

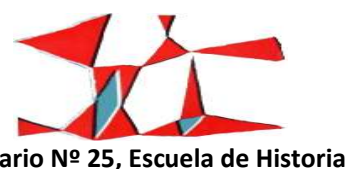


cotidianeidad en la basílica de Luján. El actual capellán castrense recordaba la dedicación de Serafini en la preparación de cada discurso. De las numerosas veces en las que debió obrar como su tipógrafo, Pesce destacaba la cantidad de revisiones a las que era sometido. Remarcó tres elementos presentes como denominadores comunes en cada uno de sus viajes y celebraciones: la simplicidad de sus palabras, la evocación de la virgen de Luján, y las reafirmaciones patrióticas. ${ }^{38}$

Anunciado Serafini fue un leal cultivador de la representación católica de la "patria". Su principio más recurrente consistía en afirmar, difundir, y conservar la "tradición católica de la Argentina" ${ }^{39}$ En la historiografía nacional se ha reflexionado acerca de esa construcción teórica y resulta poco pertinente profundizar aquí esa cuestión. ${ }^{40}$ Lo propuesto en este estudio remite a analizar cómo se produjo esa conjunción de factores que posibilitaron la reproducción de una figura del gaucho indefectiblemente católico. Allí el segundo elemento a destacar en la obra de Serafini fue la recurrente apelación a los símbolos patrios en una perspectiva nacionalista que teñía gran parte de su discurso. "Demos siempre primacía a Roma sobre cualquier otra capital doctrinaria en el mundo, a la Bandera de Belgrano sobre cualquier bandera de la tierra.", pregonaba en una misión en la Provincia de Chaco. ${ }^{41}$ Las agrupaciones tradicionalistas encontraron, entonces, otra característica común entre sus intereses y los del "obispo peregrino". Con el transcurso de las peregrinaciones gauchas el vínculo creció en intensidad y se consolidó como "amistad". ${ }^{42}$

La primera peregrinación a caballo se realizó el 7 de octubre de 1945. Los socios de El Rodeo cabalgaron toda la madrugada para llegar temprano a la ciudad de Luján. Desde su origen esta manifestación excedió la mera visita a la basílica, su preparación incluía una serie de números y actividades que ocupaban todo el transcurso de la jornada. El primer destino de los "gauchos", que en su entrada a la ciudad fueron escoltados por los miembros del recientemente constituido Martín Fierro, fue el palacio municipal donde fueron recibidos por el comisionado interino Adolfo Saubidet. Desde allí se trasladaron a la basílica para encontrarse con Monseñor Serafini. En una demostración que se repetiría año tras año, los

\footnotetext{
${ }^{38}$ Entrevista realizada al Sacerdote José Guido Pesce, C.A.B.A., 25 de febrero de 2013.

${ }^{39}$ Entrevista realizada al Sacerdote José Guido Pesce, C.A.B.A., 25 de febrero de 2013.

${ }^{40}$ Sobre el tema ver, entre otros, Di Stefano, Roberto y Loris Zanatta; Historia de la Iglesia Argentina: desde la conquista hasta finales del siglo XX; Grijalbo Mondadori; Buenos Aires; 2000.

41 "Los viajes del Obispo Peregrino" s/d. Archivo del CCMF. Libro de Prensa.

${ }^{42}$ Comunicado de Monseñor Anunciado Serafini, 1 de agosto de 1952. Archivo del CCER. Libro de Comunicaciones.
}

268

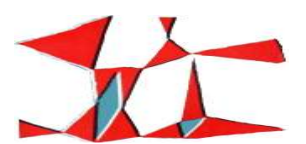

Anuario № 25, Escuela de Historia

Revista Digital № 4, Facultad de Humanidades y Artes, Universidad Nacional de Rosario, 2013 ISSN 1853-8835 
peregrinos entregaron las dos ofrendas florales que transportaban. La primera al monumento de Manuel Belgrano en la plaza que llevaba el mismo nombre, y la segunda al gaucho en la sala que se había abierto en el museo de Luján desde $1925 .^{43}$ La confluencia entre "próceres de la patria", gaucho, y religión católica alcanzaba uno de sus picos máximos de expresión. Se celebró en el centro de la plaza la misa de campaña oficiada por José Pesce, incorporando la figura del hombre de la pampa como arquetipo de la nacionalidad, que desde su institucionalización en 1939 pretendía difundirse, a la nómina de héroes patrios que la historiografía tradicional había descripto. Según su testimonio, el público que asistía a esa inusual celebración, no se extrañaba de la puesta en escena al ver, por ejemplo, a un acólito vestido completamente a la usanza gaucha colaborando con el sacerdote en el altar: "la gente lo recibía como algo propio, lo autóctono, se juntaba una gran convocatoria y se percibía una encantada aceptación." ${ }^{44}$ Los bailes y las danzas nativas que se ejecutaban luego del almuerzo criollo representaban un estímulo extra para la expectativa de los concurrentes. Con el transcurso del tiempo se fueron incorporando las carreras de sortijas en las que se destacaron los miembros del círculo criollo que vio su origen al calor de esa peregrinación.

Las manifestaciones "gauchas" experimentaron un crecimiento en organización y participantes en los años sucesivos. Cabe destacar la realización en 1947 que tuvo la particularidad de incorporarse a los festejos por el Primer Congreso Mariano Nacional. Ese acontecimiento resultó significativo para la Iglesia Católica argentina. El arzobispo de Salta, Roberto Tavella, por ejemplo, expresó con "júbilo y confianza" la adhesión de su arquidiócesis en una carta abierta a sus feligreses. ${ }^{45}$ Para esa ocasión Serafini se ocupó de que se formara una comisión de la ciudad de Mercedes para integrarse a la peregrinación. Los "gauchos" llegaron a Luján junto con las diferentes entidades y adeptos que solían participar anualmente en el Día del Camino. ${ }^{46}$ Un representante de la comitiva mercedina reconocía las gestiones del religioso en relación a la tradición: "el culto a la tradición, noblemente entendida, es prenda de patriotismo y brote de nacionalidad [...] Luján es un nexo de unión con el pasado y a la vez una antorcha que ilumina el sendero a recorrer en el

\footnotetext{
${ }^{43}$ Blasco, Elida; "La fundación del Museo Colonial e Histórico de la Provincia de Buenos Aires. Cultura y política en Luján, 1918"; en Boletín del Instituto de Historia Argentina y Americana Dr. Emilio Ravignani; Facultad de Filosofía y Letras UBA-Eudeba; № 25; Buenos Aires; 2004.

${ }^{44}$ Entrevista realizada al Sacerdote José Guido Pesce, C.A.B.A., 25 de febrero de 2013.

${ }^{45}$ La Perla del Plata, Órgano del Santuario de Nuestra Señora de Luján. N 3, Año 57, marzo de 1947.

${ }^{46}$ La Prensa; 6 de octubre de 1947.
}

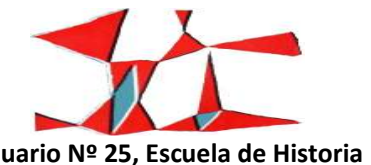


futuro. Monseñor Serafini contribuye a mantener encendido ese fuego sagrado." ${ }^{47}$ La influencia del obispo de Mercedes continuó marcando el ritmo de esas festividades. Las peregrinaciones siguieron programándose en el mes de octubre. Serafini ejercía un protagonismo activo en la organización, él asignaba las fechas para la manifestación y se encargaba también de conseguir diversos números artísticos. $^{48}$

Las primeras peregrinaciones estudiadas aquí no parecieran presentar un contenido político manifiesto. Empero, como ya se ha señalado para el devenir institucional de la agrupación El Rodeo, subyace una serie de afinidades con el gobierno de Perón que emergen en diferentes oportunidades. El párroco encargado de las primeras misas de campaña, José Guido Pesce, testimoniaba un vínculo personal con el presidente que determinó su expuesta autoproclamación como "cura peronista". ${ }^{49}$ Su filiación con el líder no vaciló con el paso del tiempo, Pesce fue encargado de oficiar la misa en el traslado de los restos de Perón en $2006 .{ }^{50}$ El mencionado Orlando Binaghi, quién era encargado de animar las peregrinaciones desde los alto parlantes, también había manifestado su adhesión por el peronismo. Sin embargo, las expresiones que se registraron durante las celebraciones resultan escasas. En octubre de 1953, un periódico de la zona de Moreno aseguraba que los peregrinos iban a pedir por el Segundo Plan Quinquenal. La caravana se detuvo frente a un monumento de Eva y se la victorió junto con el nombre de Juan Perón. ${ }^{51}$

Los testimonios que dejó la prensa escrita, sobre todo los medios locales que solían cubrir esos acontecimientos, evidencian una reconfiguración de la figura del gaucho bajo patrones religiosos y particularmente católicos. La Perla del Plata, órgano de la basílica de Luján dirigido por el párroco Armando Serafini, quién no tenía vínculo familiar alguno con Anunciado, en su cobertura de la peregrinación de 1948 expresaba: "En el pecho de cada uno de nuestro gauchos, ardorosa late la fe y el amor a Dios y a la virgencita criolla [...] gauchos y paisanas aúnan su profundo sentir tradicionalista con una devoción ilimitada

\footnotetext{
47 “Peregrinación Hípica al Santuario de la Virgen de Luján”, Doctrina, 1947. Archivo del CCER. Libro de Prensa.

48 Comunicado del Obispado de Mercedes, 14 de septiembre de 1950. Comunicado del Notario Eclesiástico del Obispado de Mercedes, 6 de septiembre de 1951. Comunicado del Obispado de Mercedes, 7 de octubre de 1952. Archivo del CCER. Libro de Comunicaciones.

${ }^{49}$ Entrevista realizada al Sacerdote José Guido Pesce, C.A.B.A., 25 de febrero de 2013.

${ }^{50}$ Página 12; 24 de enero de 2010.

${ }^{51}$ Nuevos Rumbos; Merlo-Moreno; 20 de octubre de 1953.
}

270

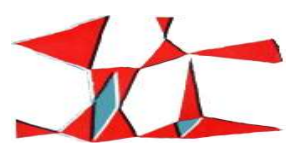

Anuario № 25, Escuela de Historia

Revista Digital № 4, Facultad de Humanidades y Artes, Universidad Nacional de Rosario, 2013 ISSN 1853-8835 
hacía la dulcísima Madre de Dios". ${ }^{52}$ Esa representación del hombre de la pampa encontraba, entonces, otro canal de expresión que complementaba lo difundido en el desarrollo de las celebraciones. "Con la fe puesta en el todopoderoso y en la patria", encabezaba la noticia el periódico Doctrina para narrar en detalle lo vinculado a la segunda peregrinación a Luján. ${ }^{53}$ Con efervescencia "patriótica" se adhería el gaucho, en tanto "arquetipo de la tradición", a la devoción dogmática por la virgen y la prensa no vacilaba en confirmar esa identificación que se divulgaba desde los sectores mencionados.

\section{Circulo Criollo Martín Fierro, fundación y mecenazgo extranjero}

El encuentro con los dirigentes de El Rodeo en abril de 1945 motivó al grupo de corredores de sortija de Algodonera Flandria y Linera Bonaerense a conformar un centro tradicionalista. ${ }^{54}$ El Círculo Criollo Martín Fierro emergió con una particularidad que no era común de hallar en las agrupaciones existentes. La entidad autoconvocada a "cultivar la tradición nacional" se creó, subsistió y se desarrolló bajo el mecenazgo de un extranjero. Julio Steverlynck fue el belga fundador de la industria textil que dio vida al pueblo de Villa Flandria. ${ }^{55}$ La historiadora Mariela Ceva ha estudiado en profundidad la constitución de la Algodonera Flandria. Sus trabajos aportan elementos considerables para analizar la participación de Julio Steverlynck y su relación con el catolicismo social. Ceva destaca, como fundamento del paternalismo practicado por el belga, los principios sociales presentes en las encíclicas Rerum Novarum y Cuadragesimo anno que tanto protagonismo ocuparan en el desarrollo de la textil. ${ }^{56}$ En la figura de Steverlynck recaían todas las actividades desarrolladas en torno al lugar. La agrupación "gaucha" no iba a ser la excepción, desde el momento de su concepción la subordinación a los deseos de "Don Julio" representaron una constante. Al analizar los archivos datados en los encuentros originarios se puede advertir que el vínculo entre los socios del círculo y el empresario continuaba con las características de patrón-empleado que se manejaba en la textil. La figura patriarcal del belga se trasladaba a las interacciones entre los miembros de la agrupación. En

\footnotetext{
52 La Perla del Plata, Órgano del Santuario de Nuestra Señora de Luján. № 12, Año 58, diciembre de 1948.

53 “Peregrinación Hípica al Santuario de la Virgen de Luján”, Doctrina, 1947. Archivo del CCER. Libro de Prensa.

${ }^{54}$ Acta fundacional del CCMF, 8 de mayo de 1945. Archivo del CCMF. Libro de Actas.

${ }^{55}$ Ver Cronología, síntesis biográfica y acontecimientos de la vida de Don Julio Steverlynck y de su pueblo Villa Flandria y zonas aledañas, en Archivo del CCMF.

${ }^{56}$ Ceva, Mariela; Empresas, trabajo e inmigración en la Argentina. Los casos de la Fábrica Argentina de Alpargatas y la Algodonera Flandria (1887-1955); Biblos; Buenos Aires; 2010.
}

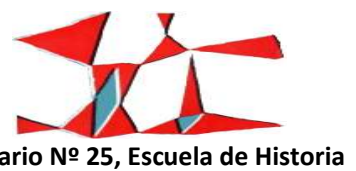


Julio Steverlynck se encuentra otro de los factores que contribuyeron al desarrollo de las peregrinaciones gauchas.

Julio Alois Steverlynck creció en un hogar estrictamente religioso. Sus padres se ocuparon de su educación espiritual y desde ese ámbito se forjó un "católico hasta las últimas consecuencias". ${ }^{57}$ Son variados los aspectos de su vida que podrían considerarse en pos de analizar su figura e influencia, empero se destacará aquí lo referido a sus convicciones católicas que fomentaron, directa e indirectamente, el desarrollo de las manifestaciones gauchas en el santuario de Luján. El sacerdote Silvio de Schrijver explicó cómo la encíclica Rerum Novarum, escrita por el Papa León XIII en 1891, había marcado el trayecto laboral de Julio Steverlynck: "aplicaba la doctrina social de la iglesia en el trato con los obreros". ${ }^{58}$ Algodonera Flandria resultó pionera en varias mejoras laborales para sus trabajadores. Además de los derechos conquistados obtuvo amplia repercusión el plan de viviendas que se ponía a disposición de sus empleados. ${ }^{59}$ Ese católico nacido en Countrai, Bélgica, que se preocupó por sostener sus ritos dominicales y participar de la Eucaristía aún en su servicio durante la Primera Guerra Mundial, fomentó sus valores religiosos e intentó difundirlo de distintas maneras entre los trabajadores. La banda musical por él formada, bautizada igual que la encíclica papal, fue solicitada en oportunidades por Monseñor Anunciado Serafini para alcanzar una mayor convocatoria durante las festividades de las peregrinaciones gauchas. ${ }^{60}$ Los dos monumentos que se erigían en el patio interno de la algodonera, en honor a las encíclicas: Rerum Novarum, y Quadragesimo Anno, ${ }^{61}$ las capillas y parroquias construidas en Villa Flandria, las recurrentes bendiciones y celebraciones religiosas, ${ }^{62}$ son algunas muestras del celo católico que movilizaba el accionar de Julio Steverlynck.

El devenir de la agrupación Martín Fierro estuvo ligado a las voluntades y subvenciones del empresario belga. Las gestiones previas al encuentro fundacional evidenciaron lo que sería una constante

\footnotetext{
${ }^{57}$ El Telar; Flandria. Año XLI, N 425. 1975-1976.

${ }^{58}$ El Telar; Flandria. Año XLI, N 425. 1975-1976. Ver Encíclica en:

http://www.vatican.va/holy father/leo xiii/encyclicals/documents/hf I-xiii enc 15051891 rerum-novarum sp.htm

${ }^{59}$ Esquiú; Buenos Aires; 7 de diciembre de 1976. Cronología, síntesis biográfica y acontecimientos de la vida de Don Julio Steverlynck y de su pueblo Villa Flandria y zonas aledañas, en Archivo del CCMF.

${ }^{60}$ Comunicado del Obispado de Mercedes, 7 de octubre de 1952. Archivo del CCER. Libro de Comunicaciones.

${ }^{61}$ El Telar; Flandria. Año XLI, N 425. 1975-1976. Ver encíclicas en: http://www.vatican.va/holy father/pius xi/encyclicals/documents/hf p-xi enc 19310515 quadragesimo-anno sp.html; http://www.vatican.va/holy father/leo xiii/encyclicals/documents/hf I-xiii enc 15051891 rerum-novarum sp.html

${ }^{62}$ Cronología, síntesis biográfica y acontecimientos de la vida de Don Julio Steverlynck y de su pueblo Villa Flandria y zonas aledañas, en Archivo del CCMF.
}

272

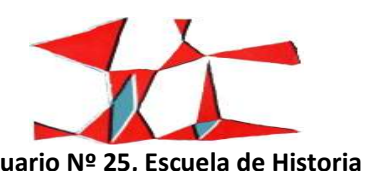


en el funcionamiento de la entidad. Recién cuando los impulsores del proyecto contaron con la "bendición de Don Julio" se puso en marcha la preparación para la reunión inaugural. ${ }^{63}$ Nombrado presidente honorario de la institución, su función no se remitió sólo a la aprobación o reprobación de diversas actividades y tareas. Durante los primeros años de la agrupación gaucha la organización interna evidenció problemáticas complejas que obstaculizaron su desarrollo y crecimiento. Desde la sorpresiva acta de disolución que firmaron unilateralmente algunos miembros de la comisión directiva, pasando por la intervención de los socios hasta la anulación de la misma y la restitución del centro, los conflictos ocuparon gran parte de las reuniones y asambleas. ${ }^{64}$ Steverlynck sostuvo un rol activo en el control económico e institucional del círculo. En 1950, ante algunos desajustes en las cuentas internas, "Don Julio" mandó a pedir los libros de caja y luego de una exhaustiva revisión envió una auditoria sobre la institución que determinó la expulsión del entonces tesorero, Blas Castellón. ${ }^{65}$

El centro tradicionalista de Jáuregui colaboró con la realización de las peregrinaciones, sin embargo, en este período estudiado que podría considerarse fundacional, sostuvo un rol de coparticipación. La organización durante esos primeros años resultó una obra conjunta del obispo Serafini y del círculo criollo El Rodeo. Entre ellos se definía la fecha y la elaboración del programa de festejos. Martín Fierro aceptaba las invitaciones, los recibía en las afueras de Luján y participaba en los números artísticos. ${ }^{66}$ Se puede considerar que los esfuerzos estaban dirigidos, principalmente, a consolidar la organización interna y el cotidiano funcionamiento de la entidad. No obstante, institucionalmente se mostró siempre comprometida con el evento. La comisión directiva fomentaba la participación entre los socios y, en una muestra del carácter reglamentado del tradicionalismo que profesaban, se adjudicaban el derecho de citar a los miembros que no asistían a las peregrinaciones para que realicen su descargo y fundamenten sus explicaciones. ${ }^{67}$

\footnotetext{
${ }^{63}$ Acta fundacional del CCMF, 8 de mayo de 1945. Archivo del CCMF. Libro de Actas.

${ }^{64}$ Acta de la Comisión Directiva del CCMF, 21 de julio de 1946. Acta de la Comisión Directiva del CCMF, 7 de agosto de 1947. Archivo del CCMF. Libro de Actas.

${ }^{65}$ Acta de la Comisión Directiva del CCMF, 23 de abril de 1950. Archivo del CCMF. Libro de Actas.

${ }^{66}$ Acta de la Comisión Directiva del CCMF, 2 de octubre de 1946. Acta de la Comisión Directiva del CCMF, 16 de octubre de 1949. Acta de la Comisión del CCMF, 16 de septiembre de 1950. Archivo del CCMF. Libro de Actas.

${ }^{67}$ Acta de la Comisión Directiva del CCMF, 11 de octubre de 1950. Archivo del CCMF. Libro de Actas.
}

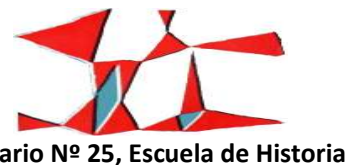




\section{Conclusiones}

Las peregrinaciones gauchas se consolidaron como una práctica religiosa en la cuál, no sólo se manifestaba la fe de sus participantes, sino también se difundía una representación particular del gaucho. La religión del hombre de la pampa había despertado diversas interpretaciones en la historia y literatura argentina. Carlos Astrada, en El mito gaucho, ocupa buena parte de su estudio analizando el carácter laico del gaucho, desligándolo de la "roña hispano católica". ${ }^{68}$ Ibrahim Hallar sostiene la filiación guacho-árabe en un trabajo que reseña consideraciones de diferentes autores para afirmar que "nunca se le inculcó principios religiosos". ${ }^{69}$ Empero, la representación del gaucho como arquetipo de la nacionalidad argentina, que profesaban los centros tradicionalistas y que había institucionalizado el gobierno provincial en 1939, resultaba incompatible con esas caracterizaciones. En las prácticas socio-culturales aquí estudiadas se celebró la integración del "símbolo de la nacionalidad" con la religión oficial del estado. Argentina era una nación católica y el referente identitario reivindicado también debía serlo.

Las peregrinaciones gauchas resultan significativas, también, por evidenciar el proceso -que es anterior a esas actividades- de masculinización de la fe. De los gauchos que, según los relatos de la tradición oral, esperaban montados en sus caballos la finalización de la misa afuera de la capilla, se dio paso a los "gauchos" de la década del cuarenta que organizaban y participaban con roles protagónicos las profesiones de fe. La mujer había ostentado la potestad sobre las devociones religiosas hasta principios de siglo XX y el culto de la Virgen María había sido asociado, sobre todo en la época colonial, al modelo de femineidad. ${ }^{70} \mathrm{El}$ hombre, no sólo los "gauchos", intensificó su participación para el período aquí estudiado. El obispo de Mercedes recibió en 1946, por ejemplo, la IV peregrinación a pie desde esa ciudad a la basílica de Luján integrada "solamente por hombres y jóvenes". ${ }^{71}$

El repaso por los orígenes de esas manifestaciones gauchas permite identificar dos actores protagónicos en su puesta en marcha y consolidación. Las particularidades que identificaban la actividad pastoral de Monseñor Serafini resultaron un factor clave para comprender su participación en esos eventos.

\footnotetext{
${ }^{68}$ Astrada, Carlos; El Mito Gaucho; Ediciones Cruz del Sur; Buenos Aires; 1964; pp. 2-10.

${ }^{69}$ Hallar, Ibrahim; El Gaucho, su originalidad arábiga; Buenos Aires; 1962; pp. 2-11.

${ }^{70}$ Fogelman, Patricia; "El culto mariano y las representaciones de lo femenino. Recorrido historiográfico y nuevas perspectivas de análisis"; en La Aljaba; V.10; ene/dic 2006.

${ }^{71}$ El Pueblo; 9 de noviembre de 1946.
}

\section{4}

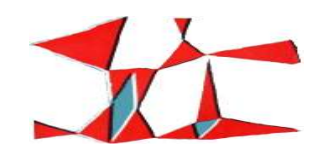

Anuario № 25, Escuela de Historia

Revista Digital № 4, Facultad de Humanidades y Artes, Universidad Nacional de Rosario, 2013 ISSN 1853-8835 
El contenido patriótico que atravesaba sus discursos y homilías, su afán por peregrinar la imagen de la virgen de Luján en los pueblos del interior, y su continua búsqueda en orden a incrementar el número de feligreses, ${ }^{72}$ posibilitaron su encuentro con el Círculo Criollo El Rodeo. Esa agrupación había manifestado su adhesión católica desde el momento de su fundación. Los principales dirigentes de la entidad se habían formado en familias que profesaban la fe y reprodujeron esas convicciones al funcionamiento institucional. Lo cierto es que, durante 1945, la interacción dio lugar a la primera peregrinación a caballo institucionalizada.

Los socios peregrinos que iniciaban sus cabalgatas no marchaban en su nombre. En primer lugar, lo hacían en nombre de su agrupación con la cual desarrollaban un alto grado de referencia identitaria. En segundo lugar, se consideraban fieles representantes del "gaucho argentino" que acorde a su interpretación era el máximo exponente de la nacionalidad. Sus prácticas, por tanto, difundían un mensaje que excedía los intereses personales. Los protagonistas de esas manifestaciones, algunos con mayor conciencia que otros, diseminaban una figura del gaucho adherido, no sólo a los preceptos, sino también a las prácticas de la Iglesia, que resultaba aún más funcional a la pretendida representación de arquetipo de la tradición nacional. Para que esa caracterización resultara eficaz esos centros tradicionalistas desarrollaron un cierto grado de normativa reglamentada que delimitaba los márgenes de posibilidades al interior de las instituciones. La figura del belga Julio Steverlyck en el Círculo Criollo Martín Fierro plasma un acertado ejemplo de lo mencionado. Su compromiso con las doctrinas de la Iglesia redundó en un estímulo constante para que la nueva agrupación se comprometiera en la consolidación de las peregrinaciones a caballo. Se inauguraba así un espacio de interacción que involucraba, también, dirigentes políticos y funcionarios. La representación del gaucho como católico se fortalecía, entonces, en la convergencia de esas instituciones que participaban, en diversos niveles y con variada intensidad, en las peregrinaciones al santuario de Luján.

Recibido: 22 de septiembre de 2013

Aprobado: 1 de diciembre de 2013

Versión final: 18 de diciembre de 2013

\footnotetext{
${ }^{72}$ Entrevista realizada al Sacerdote José Guido Pesce. C.A.B.A. 25 de febrero de 2013.
}

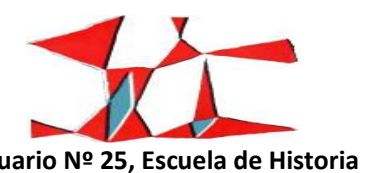

